\title{
PERBANDINGAN HASIL BELAJAR SISWA MENGGUNAKAN MEDIA CALL CARD DAN TRUTH AND DARE
}

\author{
Wise Meilan ${ }^{* 1}$, Salastri Rohiat ${ }^{2}$, Hermansyah Amir $^{3}$ \\ Program Studi Pendidikan Kimia Fakultas Keguruan dan Ilmu Pendidikan Universitas Bengkulu \\ ${ }^{1,2,3}$ Pendidikan Kimia, Jurusan PMIPA, FKIP, Universitas Bengkulu \\ e-mail : ${ }^{* 1}$ wisemeilan.wm@gmail.com
}

\begin{abstract}
Abstrack
This study aimed to compare the learning outcomes of students with using cooperative learning type Team Games Tournament (TGT) with media Call Card and Truth and Dare in SMA Negeri 05 Bengkulu Tengah. This research is quasy experimental with population all grade students in SMA Negeri 05 Bengkulu Tengah and the sample is $\mathrm{X}_{3}$ class as experiment class 1 which implement instructional media truth and dare and $X_{1}$ class as experiment class 2 which implement instructional media Call Card. Students learning outcomes in this research extend from the difference of pretest and posttest value. In the experimental class 1 average value of students learning outcomes 69,46 while the experimental class 2 at 58,21. Through a series of statistical test done hypothesis testing using $t$ test $(0,01)$ was obtained $t=3,13$ and t table $=2,39$. The results of data analysis showed that shere were significant differences in student learning result between the aplication of instructional media Truth and Dare with media Call Card in hydrocarbon compound material in X grade SMA Negeri 05 Bengkulu Tengah. This can be showed t test that has been done on student learning outcomes for cognitife aspect got the result that value $t$ table $<t$. The obtained $t=3,133$ mean while $t$ table $=2,397$.
\end{abstract}

Keywords: Truth and Dare, Call Card, TGT

\begin{abstract}
Abstrak
Tujuan penelitian untuk mengetahui Perbandingan Hasil Belajar Siswa Antara Pembelajaran Kooperatif Tipe Team Games Tournament (TGT) Menggunakan Media Media Call Card dan Truth And Dare Di Kelas X SMA Negeri 05 Bengkulu Tengah. Penelitian ini merupakan penelitian quasi eksperimen dengan populasi seluruh siswa kelas X SMA Negeri 05 Bengkulu Tengah dan sampel adalah kelas $\mathrm{X}_{3}$ sebagai kelas eksperimen 1 yang menerapkan media Truth and Dare dan kelas $\mathrm{X}_{1}$ sebagai kelas eksperimen 2 yang menerapkan media Call Card. Hasil belajar siswa pada penelitian ini dilihat dari selisih nilai pretest dan posttest. Pada kelas eksperimen 1 nilai rata-rata peningkatan hasil belajar siswa sebesar 69,46 sedangkan kelas eksperimen 2 sebesar 58,21. Melalui serangkaian uji statistik dilakukan pengujian hipotesis dengan menggunakan uji $\mathrm{t}(0,01)$ diperoleh $\mathrm{t}_{\text {hitung }}=3,13$ dan $\mathrm{t}_{\text {tabel }}=2,39$. Hasil analisis data menunjukan bahwa terdapat perbedaan yang signifikan hasil belajar siswa antara penggunaan media Truth and Dare dengan medi Call Card pada materi senyawa hidrokarbon di kelas X SMA Negeri 05 Bengkulu Tengah. Hal ini dapat dilihatkan uji t yang telah dilakukan terhadap hasil belajar siswa untuk ranah kognitif, diperoleh hasil bahwa nilai $t_{\text {tabel }}<t_{\text {hitung. }} \cdot t_{\text {hitung }}$ yang diperoleh yaitu 3,133 sedangkan $t_{\text {tabel }}$ yang diperoleh yaitu 2,397.
\end{abstract}

Kata Kunci : Truth and Dare, Call Card, TGT

\section{PENDAHULUAN}

Pendidikan memiliki peran yang penting untuk menciptakan manusia yang berkualitas dan berpotensi, oleh karenanya diperlukan proses pembelajaran yang baik agar dapat menciptakan generasi penerus bangsa yang kreatif, cerdas, handal, dan bermoral [1]. Demi memwujudkan suatu tujuan pembelajaran terutama peningkatan sumber daya manusia yang berkreativitas tinggi, proses pembelajaran dalam pendidikan sangat ditekankan. Proses yang terjadi yaitu proses penerimaan informasi untuk kemudian diolah sehingga menghasilkan keluaran dalam bentuk hasil belajar. Hasil belajar adalah kemampuan-kemampuan yang dimilki siswa setelah menerima pengalaman belajar [2].
Proses belajar mengajar merupakan proses keseluruhan dalam pendidikan yang menempatkan guru sebagai pemegang peran utama, karena proses belajar mengajar mengandung perbuatan siswa dan guru dengan dasar hubungan timbal balik agar tercapai tujuan [3]

Dari Tabel 1 dapat terlihat bahwa rata-rata nilai ulangan harian kimia kelas X tahun ajaran 2014/2015 dan 2015/2016 di SMA Negeri 05 Bengkulu Tengah masih banyak siswa belum mencapai Kriteria Ketuntasan Minimal (KKM) sebesar $=70$ terutama pada materi pokok bahasan senyawa hidrokarbon. Untuk itu di SMA Negeri 05 Bengkulu Tengah diperlukan pene-rapan model pembelajaran dan media pembelajaran yang bisa meningkatkan motivasi siswa . 
Tabel 1. Rata-Rata Nilai Ulangan Harian Kimia Kelas X Tahun Ajaran 2014/2015 dan 2015/2016 di SMA Negeri 05 Bengkulu Tengah

\begin{tabular}{llll}
\hline No & Materi & \multicolumn{2}{c}{ Tahun Ajaran } \\
& & $2014 / 2015$ & $2015 / 2016$ \\
\hline 1 & Tata Nama Senyawa & 44,61 & 48,83 \\
& Kimia & & 71,94 \\
\hline 2 & $\begin{array}{l}\text { Larutan Nonelektrolit } \\
\text { dan elektrolit }\end{array}$ & 62,15 & 38,46 \\
\hline 3 & Konsep Redoks & 37,41 & 35,85 \\
\hline 4 & Senyawa Hidrokarbon & 24,26 & \\
\hline
\end{tabular}

Salah satu model pembelajaran yang dapat digunakan adalah model pembelajaran kooperatif Teams Games Tournament (TGT). Model TGT adalah satu tipe pembelajaran kooperatif yang menempatkan siswa dalam Kelompok-kelompok belajar yang beranggotakan 5 sampai 6 orang siswa yang memiliki kemampuan, jenis kelamin dan suku kata atau ras yang berbeda. Guru menyajikan materi, dan siswa bekerja dalam kelompok mereka masing-masing, sehingga dapat menciptakan suasana yang meyenangkan [4]. Dalam model TGT untuk mencapai kesenangan dalam belajar dibutuhkan sebuah media berupa media pembelajaran yang dapat membantu menciptakan suasana tersebut, sekaligus merupakan salah satu alat bantu guru dalam menyampaikan informasi ke siswa [5]. Salah satu media yang banyak diminati siswa yaitu berupa permainan [6], antara lain adalah media Truth and Dare dan Call Card.

Media Truth and Dare merupakan suatu strategi pembelajaran yang mengajak siswa untuk belajar aktif dan bertujuan agar siswa saling bekerja sama dalam belajar serta menumbuhkan daya kreatifitas [7]. Sedangkan Media Call Card merupakan teknik pembelajaran yang membuat siswa lebih aktif dalam proses pembelajaran sehingga aktivitas belajar siswa meningkat [8].

Berdasarkan latar belakang dan permasalahan di atas penelitian Perbandingan Hasil Belajar Siswa Antara Pembelajaran Kooperatif Tipe TGT Menggunakan Media Call Card dan Truth and Dare kelas X di SMA Negeri 05 Bengkulu Tengah" perlu dilakukan.

\section{METODE PENELITIAN}

Jenis Penelitian ini yaitu penelitian eksperimental kuasi (Quasi Experimental). Penelitian ini dilakukan pada dua kelas yang memiliki kemampuan yang sama yang nantinya diberikan perlakuan yang berbeda menggunakan media pembelajaran yang berbeda pula.
Untuk kelas eksperimen pertama yaitu dengan metode pembelajaran TGT menggunakan media Truth and Dare dan kelas eksperimen kedua yaitu dengan metode pembelajaran TGT menggunakan media Call Cards.

Target populasi dalam penelitian ini adalah seluruh siswa kelas X SMA Negeri 05 Bengkulu Tengah tahun ajaran 2016-2017 yang terdiri atas 4 kelas. Pemilihan kelas sampel dilakukan secara random dan kemudian dilakukan uji homogenitas didapatkan dua kelas yang homogen.

Teknik pengumpulan data pada penelitian ini adalah observasi awal, tes hasil belajar yang terdiri dari pretest dan posttest. Teknik analisis data yang digunakan adalah nilai rata-rata kelas, uji normalitas, dan uji t.

\section{HASIL DAN PEMBAHASAN}

Penelitian ini dilakukan di SMA Negeri 05 Bengkulu Tengah pada tanggal 15 Mei dan 23 Mei 2017, populasi yang digunakan seluruh siswa/siswi kelas $\mathrm{X}$ di SMA Negeri 05 Bengkulu Tengah. Pada penelitian ini sampel yang terpilih adalah kelas X1 dan X3, dimana kelas X1 sebagai kelas eksperimen II yang menggunakan media Call Card dan kelas X3 sebagai kelas eksperimen I yang menggunakan media Truth and Dare.

Berdasarkan Tabel 2 , terlihat bahwa selisih nilai pretest dan posttest pertemuan 1 sebesar 67,73 selisih nilai pretest dan posttest pertemuan ke 2 sebesar 48,76 dan nilai rata-rata dari pretest dan ptosttest sebesar 58,22 terdapat peningkatan. Nilai rata-rata pretest dan posttest siswa masih tergolong rendah atau masih di bawah nilai standar KKM, sedangkan untuk nilai rata-rata posttest siswa sudah di atas nilai standar KKM.

Berdasar pada nilai dari standar deviasi sebesar 13,43 dan nilai varians dari kelas tersebut yaitu 180,48 menunjukan bahwa sebaran data adalah luas. Terdapat siswa yang memiliki nilai selisih antara pretest dan posttest yang tinggi atau sebaliknya, dapat disimpulkan bahwa ada siswa yang benar-benar memahami pembelajaran dan ada juga siswa yang kurang memahami pembelajaran yang diberikan.

Berdasarkan Tabel 3, terlihat bahwa selisih nilai pretest dan posttest pertemuan 1 sebesar 64,26 selisih nilai pretest dan posttest pertemuan ke 2 sebesar 69,46 dan nilai rata-rata dari pretest dan ptosttest sebesar 69,46 terdapat peningkatan. Nilai rata-rata pretest dan posttest siswa masih tergolong rendah atau masih di bawah nilai standar KKM, sedangkan untuk nilai rata-rata posttest siswa sudah di atas nilai standar KKM. Pada kelas eksperimen ini terdapat nilai standar deviasi dari pretest dan posttest yaitu 13,52 dan nilai varians dari kelas ini yaitu 183,03 . Hal ini menujukan bahwa sebaran data 
luas, dimana pada eksperimen ini memiliki standar deviasi yang lebih tinggi dari pada kelas eksperimen kedua berarti kelas eksperimen pertama lebih luas dan memiliki data yang lebih variatif dari pada kelas kedua. Semakin besar nilai standar deviasi maka data sampel semakin menyebar dan sebaliknya.

Tabel 2. Daftar Nilai Rata-Rata Kelas Eksperimen II

\begin{tabular}{llll}
\hline \multirow{2}{*}{ Komponen } & \multicolumn{2}{l}{ Nilai } & \\
\cline { 2 - 4 } & $\begin{array}{c}\text { Pertemuan } \\
1\end{array}$ & Pertemuan 2 & Rata-Rata \\
\hline Pretest & 7,67 & 25,17 & 16,42 \\
\hline Posttest & 75,4 & 73,93 & 74,64 \\
\hline $\begin{array}{l}\text { Selisih pretest dan } \\
\text { posttest }\end{array}$ & 67,73 & 48,76 & 58,22 \\
\hline Standar deviasi & 17 & 19,1 & 13,43 \\
\hline N (jumlah siswa) & 28 & 28 & 28 \\
\hline Varians & 288 & 366 & 180,48 \\
\hline
\end{tabular}

Tabel 3. Daftar Nilai Rata-Rata Kelas Eksperiman 1

\begin{tabular}{lllc}
\hline \multirow{2}{*}{ Komponen } & Nilai & & \\
\cline { 2 - 4 } & Pertemuan & Pertemuan & Rata-Rata \\
& 1 & 2 & \\
\hline Pretest & 20,54 & 15 & 17,76 \\
\hline Posttest & 84,8 & 89,6 & 87,23 \\
\hline $\begin{array}{l}\text { Selisih pretest dan } \\
\text { posttest }\end{array}$ & 64,26 & 74,6 & 69,46 \\
\hline Standar deviasi & 17,4 & 14,53 & 13,52 \\
\hline N (jumlah siswa) & 28 & 28 & 28 \\
\hline Varians & 303 & 211 & 183,03 \\
\hline
\end{tabular}

Tabel 4. Uji Normalitas

\begin{tabular}{cccc}
\hline No & Data & $\begin{array}{c}\text { Media } \\
\text { Truth and Dare } \\
\text { (eksperimen I) }\end{array}$ & $\begin{array}{c}\text { Media } \\
\text { Call Card } \\
\text { (eksperimen II) }\end{array}$ \\
\hline 1. & $\mathrm{X}_{\text {Hitung }}^{2}$ & 6,319 & 10,23206 \\
\hline 2. & $\mathrm{X}_{\text {Tabel }}^{2}$ & 11,34 & 11,34 \\
\hline
\end{tabular}

Pada kedua kelas eksperimen baik yang menggunakan media Truth and Dare dan media Call Card memperoleh nilai $\mathrm{X}_{\text {Hitung }}^{2}<\mathrm{X}_{\text {Tabel }}^{2}$ dengan menggunakan taraf signifikan 0,01 (Tabel 4). Maka dapat disimpulkan bahwa kedua kelas eksperimen terdistribusi normal, yang berarti $\mathrm{H}_{0}$ diterima karena data berasal dari populasi terdistribusi normal.

Terlihat pada Tabel 5 bahwa $\mathrm{F}_{\text {Hitung }}<\mathrm{F}_{\text {tabel }}$ dimana apabila $F_{\text {Hitung }}<F_{\text {tabel }}$ maka kedua kelas eksperimen mempunyai varians yang homogen. Varians yang homogen adalah data yang terdistribusi normal dan apabila diambil acak maka data tersebut tidak mengalami perbedaan.
Tabel 5. Tabel Uji Homogenitas

\begin{tabular}{ccc}
\hline No & Data & Hasil Perhitungan \\
\hline 1. & $\mathrm{~F}_{\text {Hitung }}$ & 1,0141 \\
\hline 2. & $\mathrm{~F}_{\text {tabel }}$ & 7,13 \\
\hline
\end{tabular}

Jika $\mathrm{F}_{\text {Hitung }}<\mathrm{F}_{\text {tabel }}$ maka $\mathrm{H}_{0}$ akan ditolak dan $\mathrm{H}_{\mathrm{a}}$ akan diterima karena terdapat perbedaan hasil belajar siswa pada ranah kognitif pada materi senyawa hidrokarbon dengan menerapkan pembelajaran kooperatif Tipe TGT dengan menggunakan media Truth and Dare dan Call Card. Homogen untuk melihat bahwa kedua kelas tersebut memiliki tingkat kemampuan kognitif yang sama atau setara, karena kedua kelas eksperimen terdistribusi normal dan memiliki varians yang homogen, maka dapat dilakukan pengujian hipotesis dengan melakukan uji t.

Model dan media yang digunakan pada proses pembelajaran dapat membuat siswa lebih mudah dalam memahami materi senyawa hidrokarbon. Akan tetapi, kedua media tersebut mempunyai perbedaan masingmasing sehingga mengakibatkan peningkatan hasil belajar siswa yang berbeda. Dari kedua media yang digunakan, peningkatan hasil belajar siswa yang lebih baik yaitu pada kelas eksperimen I yang menggunakan media Truth and Dare. Hal ini sesuai dengan penelitian yang dilakukan [9] yang menyimpulkan bahwa model pembelajaran kooperatif tipe TGT pada pembelajaran kimia yang menggunakan media cad pada materi senyawa hidrokarbon memberikan hasil prestasi belajar yang lebih baik.

Penggunaan media pada kelas eksperimen II mempunyai kelebihan menggunakan media Truth and Dare yaitu dapat menciptakan suasana kelas yang lebih hidup dan menyenangkan, sehingga antusiasme siswa terhadap pembelajaran semakin bertambah, serta mempunyai rasa tertarik terhadap soal-soal yang diberikan oleh guru dan mendapatkan hasil nilai belajar yang memuaskan, dari pada menggunakan media Call Card. Pada media Truth and Dare siswa memilih salah satu kartu yang berisi pertanyaan lalu diberi waktu 90 detik untuk berdiskusi dengan kelompok. Hal ini lebih memudahkan siswa untuk menjawab pertanyaan yang diberikan dengan jawaban benar. Hasil penelitian ini sesuai dengan hasil penelitian [10] yang menyimpulkan pembelajaran kimia yang menggunakan media Truth and Dare memiliki beberapa kelebihan dapat memciptakan suasanan yang menyenangkan dan lebih hidup sehingga siswa termotivasi untuk belajar. Sedangkan Pada media Call Card memiliki kelebihan yaitu membuat suasanan kelas lebih menyenangkan dan menghilangkan kejenuhan siswa dalam proses pembelajaran sehingga penggunaan media 
mampu meningkatkan hasil belajar siswa dapat terlihat dari peningkatan hasil belajar siswa yang mencapa nilai diatas standar KKM. Hal ini sesuai dengan penelitian yang dilakukan oleh [11] yang menyimpulkan bahwa media Call Card dapat meningkatakan hasil belajar siswa dan bepengaruh positif terhadap aktivitas pembelajaran siswa. Namun penggunaan media Call Card memiliki beberapa kekurangan yaitu siswa menjadi tidak fokus pada soal-soal yang terdapat pada kartu, fokus siswa menjadi teralihkan pada permainnya saja. Hal ini disebabkan pada media Call Card siswa yang tidak bisa menjawab pertanyaan soal akan menggambil kartu yang ada ditengah meja, sehingga fokus siswa menjadi terbagi-bagi dan siswa menjadi tidak tertarik pada soal melainkan siswa lebih tertarik memperhatikan temannya yang mengambil kartu ditengah meja. Selain itu, masih ada siswa yang sepenuhya menangkap konsep yang dikemas dalam media, hal ini dikarenakan kesempatan untuk diskusi kelompok sedikt, sehingga tidak semua anggota mendapatkan mengerjakan soal tersebut.

\section{KESIMPULAN}

Dari hasil penelitian dapat disimpulkan bahwa pembelajaran dengan model kooperatif tipe TGT menggunakan media Truth and Dare dan Call Card dapat menigkatkan hasil belajar siswa. Nilai pretest dan posttest yang menggunakan media Truth and Dare menghasilkan nilai yang lebih baik dari pada yang menggunakan media Call Card.

Terdapat perbedaan yang signifikan antara hasil belajar siswa yang menggunakan model pembelajaran kooperatif tipe TGT dengan media Call Card dan Truth and Dare dilihat dari hasil nilai ttabel<thitung yang diperoleh yaitu 3,133 sedangkan ttabel yang diperoleh yaitu 2,397 .

\section{SARAN}

Guru harus memperhatikan kondisi kelas pada eksperime II dengan media Call Card yang benar-benar harus dikuasai oleh guru agar suasana menjadi kondusif.

Dalam penerapan model pembelajaran kooperatif tipe TGT dengan media Truth and Dare dan media Call Card guru harus mempunyai perencanaan yang matang. Guru harus memperhatikan alokasi waktu, media, kondisi kelas, dan karektristik siswa. Karena proses pembelajaran tidak berjalan baik atau tidak kondusif.

\section{UCAPAN TERIMA KASIH}

Terima kepada Bapak Sahroni M.Pd selaku Kepala Sekolah SMA Negeri 05 Bengkulu Tengah, Bapak Tamrin S.Pd dan Bapak Jamalludin S.Pd selaku guru kimia, dan siswa di SMA Negeri 05 Bengkulu Tengah dan semua pihak yang telah membantu menyelesaikan penelitian ini.

\section{DAFTAR PUSTAKA}

[1] Wiwit, Amir, H, Putra, D,D, 2012, Penerapan Model Pembelajaran Kooperatif Tipe TGT Dengan dan Tanpa Penggunaan Media Animasi Terhadap Hasil Belajar Kimia Siswa SMA Negeri 9 Kota Bengkulu, EXACTA. 10(1).

[2] Ruhimat,Toto. 2013. Kurikulum dan Pemebelajaran/Tim Pengembangan MKDP Kurikulum dan Pembelajaran. PT Raja Grafindo Persada. Jakarta. ISBN: 9789797693824

[3] Slameto, 1995. Belajar dan Faktor-Faktor yang Mempengaruhinya. Jakarta: Rineka Cipta. ISBN:9789795181668[

[4] Abdullah, Husni. 2013. Penerapan Model Pembelajaran Kooperatif Tipe Teams Games Tournament (TGT) Untuk Meningkatkan Hasil Belajar IPS Siswa Sekolah Dasar. JPGSD. 1(2).

[5] Desstya. A, Haryono, Saputra. S. 2012. Pembelajaran Kimia Dengan Metode Teams Games Tournaments (TGT) Menggunakan Media Animasi dan Kartu Ditinjaun Dari Kemampuan Memori Dan Gaya Belajar Siswa. Jurnal Inkuiri. 1(3). ISSN: 2252-7893 . http://jurnal.pasca.uns ac.id

[6] Nuraeni, R. Saputro, A.N.C, Redjeki, T. 2015. Penerapan Model Pembelajaran Kooperatif Tipe Teams Games Tournament (TGT) Dilengkapi Chem Puzzle Untuk Meningkatkan Kreativitas dan Prestasi Belajar Siswa Pada Materi HidroKarbon Kelas X Semester 2 SMA Negeri 1 Kartasura Tahun Pelajaran 2013/2014. Jurnal Pendidikan Kimia. 4(1). ISSN 23379995

[7] Herliani, 2016. Penggunaan Taksonomi Solo (structure Of Observed Learning Outcomes) Pada Pembelajaran Kooperatif Truth and Dare dengan Quick On The Draw untuk Meningkatkan Keterampilan Berfikir Siswa Pada Biologi SMA. Proceeding Biology Education Conference. ISSN: 2528-5742.3(1). http://digilib.unimed.ac.id 
[8] Pasla, Jhoni. 2012. Meningkatkan Aktivitas Belajar IPS Ekonomi Pada Materi Prilaku Konsumen dan Produsen Melalui Teknik Pembelajaran Kartu Panggilan Siswa Kelas X Madrasah Aliyah Kampar Timur Kabupaten Kampar. Skripsi. http://repository.uinsuska. ac.id

[9] Dewi. A, Imam. K. 2013. Pengaruh Model Team Games Tournament Media Tournament question Cards Terhadap Hasil Belajar Siswa Pada Materi Hidrokarbon. Jurnal Pendidikan Kimia. 7(2).

[10] Priatmoko. S, Binadja. A, Putri. T. 2008. Pengaruh Media Permainan Truth and Dare Terhadap Hasil Belajar Kimia Siswa SMA dengan Visi Sets. Jurnal Pendidikan Kimia.2(1). http://journal.unnes.ac.id
[11] Machin. 2013. Pengaruh Permainan Call Cards Terhadap Hasil Belajar dan Aktivitas Pembelajaran Biologi. Jurnal Pendidikan IPA. 1(2). http://journal.unnes.ac.id

Penulisan Sitasi Artikel ini ialah :

Meilan. W, Rohiat. S, Amir, H. 2017 Perbandingan Hasil Belajar Siswa Menggunakan Media Call Card dan Truth and Dare, Alotrop, 1(1):39-43 